\title{
Drug administration errors - time for national action
}

Medical errors are not uncommon, and they may cause patient morbidity and mortality and significantly increase health care costs. In 1999, it was estimated that up to 98000 Americans might have died annually as a result of medical errors. ${ }^{1}$ Drug administration errors are significant contributors to this problem. The risk of errors in anaesthesia may be higher than other specialties. ${ }^{2}$ An anaesthetist may administer a quarter of a million drugs during his or her professional career, ${ }^{3}$ many of these extremely potent drugs, frequently administered within a brief period.

For many years - and more particularly in recent years - the anaesthetic literature has been concerned about drug errors in anaesthesia. Several solutions have been suggested to decrease the problem; ${ }^{4-10}$ these include educating and raising awareness about medication safety, reading and re-reading labels on drug ampoules, checking the ampoule label with a second person or device (e.g. bar code reader), labelling all syringes in theatre, adhering to the international standard of colour-coded syringe labels, improving the organisation of drug drawers and work space, informing anaesthetists of new formulations or packaging of drugs, and establishing a mechanism for reporting and reviewing errors.

In this issue of the $S A M J$, Labuschagne et al. report on errors in drug administration by anaesthetists in public hospitals in the Free State province. ${ }^{11}$ They confirm the problem of drug administration errors in anaesthesia, with nearly $40 \%$ of respondents admitting to making a drug administration error at some stage in their career. Their investigation, which polled full-time and occasional anaesthetic providers, supports the $90 \%$ incidence of responders reporting errors in previous South African surveys. ${ }^{12,13}$ An expected finding in surveys of this nature is that a longer, full-time career in the specialty is more likely to be associated with a higher incidence of errors. This type of survey is useful to measure the occurrence of uncommon but potentially severe consequences, as it measures errors in very large numbers of cases, but lacks a denominator. ${ }^{14}$ More accurate evidence on the actual incidence of drug errors during the delivery of anaesthetics is available from prospective studies such as that of 30412 anaesthetics conducted in 3 South African teaching hospitals. The latter demonstrated a minimum incidence, of an error or near-miss, of 1 in every 274 anaesthetics administered, equating to approximately 6 incidents per month in each hospital. ${ }^{15}$ This figure is in keeping with a prospective study from New Zealand that demonstrated an incidence of errors of 1:133 anaesthetics. ${ }^{16}$ Another study from New Zealand suggests that by scanning bar codes on ampoules with a visual and auditory prompt to identify the drugs before drawing them up, together with conventional solutions suggested above, the rate of drug errors may be reduced by approximately a third. ${ }^{17}$

Although most errors do not result in major morbidity or death, a significant number can potentially seriously harm patients, e.g. wrong site injections such as that documented by Labuschagne, where a patient was left with serious neurological damage. Accidental administration of vasopressors may be the error with the greatest potential to contribute to morbidity and mortality. In the study by Labuschagne, 4 errors (12.2\%) were due to the inadvertent administration of adrenaline instead of atropine or fentanyl. Although no adverse consequences were reported, subtle organ damage cannot be excluded. That one of the most common errors in this study remains the substitution of suxamethonium for fentanyl, indicates the poor response in South Africa to publications identifying the problem, highlighting causative factors, and suggesting preventive measures. ${ }^{10,18}$
Labuschagne's work confirms earlier surveys that anaesthetists in South Africa would like a formal mechanism for reporting errors to be implemented. ${ }^{13}$ The majority identified the South African Society of Anaesthesiologists (SASA) as the preferred organisation to take responsibility for this task. The procedure could take the form of an online, anonymous reporting system freely accessible to all anaesthetic providers. Data collected nationally should be used to identify the causes of errors and provide a rational basis for instituting remedial action.

Poor ampoule labelling remains a major cause of substitution errors. Gordon suggested in 2004 that SASA should be involved with the pharmaceutical industry to improve and standardise ampoule labels. Despite approaches to the South African Bureau of Standards (SABS), by SASA, very little has been achieved in this regard.

Drug-class-specific colour-coded syringe labels are used internationally to reduce errors. In 2009, the SABS approved a new standard for colour-coded syringe labelling in theatres (SANS 26825:2009) in line with the international ISO standard. The standard provides recommendations for the colour, size, design, general properties and typographical characteristics of the labels, and can be ordered from the SABS website https://www.sabs.co.za. ${ }^{19}$ It is disappointing to note that less than a quarter of respondents in the current survey were aware of the South African standard, and only a quarter of these made regular use of it.

Labuschagne's study highlights the lack of any co-ordinated response by clinicians and managers to address the repeatedly documented occurrence of preventable drug administration errors on patients in operating theatres in South Africa. It is time for medical schools, SASA, the Department of Health, and the Medicines Control Council, together with pharmaceutical companies, the SABS, anaesthetic providers, and public and private hospitals to work together and take the necessary steps to prevent and reduce these errors.

Undergraduates at medical schools should receive lectures in patient safety as part of their curriculum. The possibility of medication errors and how to prevent them should also be emphasised during intern and registrar training.

Colour-coded syringe labels meeting the SABS standard should be available in all operating theatres throughout South Africa. While the efficacy of colour coding labels may still be the subject of debate, there is growing evidence that they contribute to patient safety and may decrease the danger of substitution errors from a different drug class. ${ }^{17}$

Both private sector and state sector drug procurement agencies should engage pharmaceutical companies to improve the standard of ampoule labelling and recognition. The technology exists in South Africa to consider bar coding of ampoules and employing the use of computer-generated audio and visual prompts, as advocated by Merry and Webster., ${ }^{9,17}$ South Africa must develop a standard for ampoule labelling similar to that adopted in the USA and Canada. This will require collaboration between the SABS, Medicines Control Council and the pharmaceutical industry.

The time has come to start implementing the necessary steps to reduce these largely preventable errors.

\section{R L Llewellyn \\ P C Gordon}

\section{A R Reed}

Department of Anaesthesia

University of Cape Town and

Groote Schuur Hospital

Cape Town 
1. Kohn LT. To err is human: building a safer health care system. Washington DC: National Academy Press, 1999.

2. Building a safer NHS for Patients: Improving Medication Safety. A Report by the Chief Pharmaceutical Officer. Smith J, ed. London: Department of Health, 2004. http://www.dh.gov.uk/ assetRoot/04/07/15/07/04071507.pdf (accessed 7 March 2011).

3. Merry A, McCall Smith A. The Human Factor. In Merry A, McCall Smith A. Errors, Medicine and the Law. Cambridge: Cambridge University Press, 2001: 46

4. Cooper JB, Newbower RS, Long CD, McPeek B. Preventable anesthesia mishaps: a study of human factors. Anesthesiology 1978;49:399-406.

. Cooper JB, Newbower RS, Kitz RJ. An analysis of major errors and equipment failures in anesthesia management: considerations for prevention and detection. Anesthesiology 1984;60:34-42.

6. Currie M, Mackay P, Morgan C, et al. Anaesth Intens Care 1993;21:596-601.

7. Orser BA. Medication safety in anesthetic practice: first do no harm. Can J Anesth 2000;47(11):1051-1054. Fasting S, Gisvold SE. Adverse drug errors in anesthesia, and the impact of coloured syringe labels. Can J Anesth 2000;47(11):1060-1067.

Merry AF, Webster CS, Mathew DJ. A new, safety-orientated, integrated drug administration and automated anesthesia record system. Anesth Analg 2001;93:385-390.

10. Jenson LS, Merry AF, Webster CS, Weller J, Larsson L. Evidence-based strategies for preventing drug administrative errors during anaesthesia. Anaesthesia 2004;59:493-504.
11. Labuschagne M, Robbetze W, Rozmiarek J, et al. Errors in drug administration by anaesthetists in public hospitals in Free State Province. S Afr Med J 2011;101:\{Insert page no's - this issue.\}

Gordon PC. Wrong drug administration errors among anaesthetists in a South African teaching hospital. SAJAA 2004;2:7-8.

13. Gordon PC Llewellyn RL, James MFM. Drug administration errors by South African anaesthetists - a survey. S Afr Med J 2006;96:630-632.

4. Glavin RJ. Drug errors: consequences, mechanisms, and avoidance. Br J Anaesth 2010;105(1):76-82.

15. Llewellyn RL, Gordon PC, Wheatcroft D, et al. Drug administration errors: a prospective survey from three South African teaching hospitals. Anaesth Intensive Care 2009;37(1):93-98.

16. Webster CS, Merry AF, Larsson L, McGrath KA, Weller J. The frequency and nature of drug administration errors during anaesthesia. Anaesth Intensive Care 2001;29:494-500.

17. Webster CS, Larsson L, Frampton CM, et al. Clinical assessment of a new anaesthetic drug administration system: a prospective, controlled, longitudinal incident monitoring study. Anaesthesia 2010;65:490-499.

18. Woods I. Making errors: admitting them and learning from them. Anaesthesia 2005;60:215-219.

19. Gordon PC, Reed AR, Llewellyn RL, Joubert I. User applied drug labels in anaesthesia: time for action. Southern African Journal of Anaesthesia and Analgesia 2009;15(5):9. 